\title{
Synthesis of New Blue Fluorescent Polymerizable 1,8-Naphthalimides and Their Copolymers with Styrene as Sensors for Fe(III) Cations
}

\author{
Ivo Grabchev, ${ }^{1,2}$ Stanislava Yordanova, ${ }^{3}$ Stanimir Stoyanov, ${ }^{3}$ and Ivan Petkov ${ }^{3}$ \\ ${ }^{1}$ Faculty of Medicine, Sofia University "St. Kliment Ohridski”, 1 Koziak Street, 1407 Sofia, Bulgaria \\ ${ }^{2}$ Chemistry Department, Faculty of Science, King Abdulaziz University, Jeddah 21589, Saudi Arabia \\ ${ }^{3}$ Faculty of Chemistry and Pharmacy, Sofia University "St. Kliment Ohridski", 1 James Boucher Boulevard, 1164 Sofia, Bulgaria
}

Correspondence should be addressed to Ivo Grabchev; i.grabchev@chem.uni-sofia.bg

Received 15 May 2013; Revised 30 September 2013; Accepted 17 October 2013; Published 5 January 2014

Academic Editor: Pasquale Longo

Copyright (C) 2014 Ivo Grabchev et al. This is an open access article distributed under the Creative Commons Attribution License, which permits unrestricted use, distribution, and reproduction in any medium, provided the original work is properly cited.

\begin{abstract}
The synthesis, characterization, and functional properties of two new polymerizable 1,8-naphthalimides (MDs) have been described. Their copolymers with styrene designed to act as a fluorescence PET chemosensor have been investigated. The study also reports the influence of different metal cations $\left(\mathrm{Ag}^{+}, \mathrm{Mg}^{2+}, \mathrm{Cu}^{2+}, \mathrm{Sr}^{2+}, \mathrm{Co}^{2+}, \mathrm{Pb}^{2+}\right.$, and $\left.\mathrm{Fe}^{3+}\right)$ on the fluorescence intensity of both low and high molecular weight fluorophores.
\end{abstract}

\section{Introduction}

In the recent years the development of molecular recognition and sensing systems for different analytes has received considerable attention. Fluorescent chemosensors utilised for detection of metal cations and protons in the environment were based on different molecular structures $[1,2]$. The fluorescent polymers are very attractive for this purpose. In this case the fluorescent sensor units can be covalently bonded to the polymer chain, thus showing very similar effect to their monomeric sensor units [3]. The functional characteristics of polymer chemosensors can be expressed either by conformational changes of macromolecules or by the collective transport properties.

Recently, new polymerizable 1,8-naphthalimide molecules to sensitive protons or metal cations have been synthesized and their functional properties are investigated. Due to the presence of a polymerizable group they can react with some commercial monomers, allowing copolymers with a green or blue fluorescence to be obtained. It was demonstrated that the copolymers of these polymerizable sensors can be used as homogeneous and heterogeneous photoinduced electron transfer (PET) fluorescent sensors sensitive to metal cations
[4-9]. In all cases 1,8-naphthalimides are enough thermoand water resistible so the polymers can be used for ion determination in solution without contaminating it. The scientific tasks on development of polymeric systems for detection of environment pollutants will be focused on finding such polymeric systems which have specific chemical, physical, and mechanical properties as transparency, resistance to different environment factor and the harmful chemical substances, flexibility, and so forth.

In this paper we present the synthesis and functional properties of two new polymerizable 1,8-naphthalimides (MDs) and their copolymer with styrene designed to act as fluorescence chemosensors. The influence of different metal cations on the fluorescence intensity of both low and high molecular weight sensors has been investigated and discussed.

\section{Experimental Part}

2.1. Materials and Methods. 4-Amino-N-allyl-1,8-naphthalimide was synthesized according to the method described previously [10]. Commercial styrene (St) was used after 
purification by distillation under reduced pressure. Dibenzoyl peroxide (DBP) (Fluka), crystallized from chloroform to methanol was used as an initiator of the free radical polymerization. Chloroacetyl chloride, piperidine, and dimethylamine were used as obtained from MERCK.

$\mathrm{UV} /$ vis spectrophotometric investigations were performed using “Thermo Spectronic Unicam UV 500” spectrophotometer. The fluorescence spectra were taken from a "Cary Eclipse" spectrophotometer. All spectra were recorded using $1 \mathrm{~cm}$ path length synthetic quartz glass cells. Fluorescence quantum yield was determined on the basis of the absorption and fluorescence spectra, using anthracene as reference $\left(\Phi_{\text {st }}=0.27[11]\right)$. All absorption and fluorescence measurements were carried out at $1 \times 10^{-5} \mathrm{~mol} \mathrm{~L}^{-1}$ for MDs. The polymer concentrations in the solutions for all measurements were $5 \mathrm{~g} \mathrm{~L}^{-1}$.

The effect of the metal cations on fluorescence intensity has been measured by adding a few microliters of stock aqueous solution $\left(c=10^{-2} \mathrm{~mol} \mathrm{~L}^{-1}\right)$ of the metal cations to a known volume of the solution $(3 \mathrm{~mL})$ in acetonitrile for monomeric sensors and in aqueous solution for polymeric sensor. This addition was limited to $0.08 \mathrm{~mL}$, so that dilution remained insignificant [12]. For all absorbance and fluorescence measurements the polymer thin film was placed diagonally in the sample quartz cuvette to improve measurement reproducibility. The reproducibility of the results was 99\%. $\mathrm{MgCl}_{2} \cdot 6 \mathrm{H}_{2} \mathrm{O}, \mathrm{Pb}\left(\mathrm{NO}_{3}\right)_{2}, \mathrm{SrCl}_{2}, \mathrm{FeCl}_{3} \cdot 6 \mathrm{H}_{2} \mathrm{O}, \mathrm{AgNO}_{3}$, $\mathrm{CuSO}_{4} \cdot 5 \mathrm{H}_{2} \mathrm{O}$, and $\mathrm{Co}\left(\mathrm{NO}_{3}\right)_{2} \cdot 6 \mathrm{H}_{2} \mathrm{O}$ were investigated as sources of metal cations.

IR analysis of compounds was carried out using the infrared Fourier transform spectrometer (IRAffinity-1 "Shimadzu") with the diffuse-reflectance attachment (MIRacle Attenuated Total Reflectance Attachment). The NMR spectra were obtained from a Bruker DRX-250 spectrometer, operating at 250.13 and $62.90 \mathrm{MHz}$ for ${ }^{1} \mathrm{H}$ and ${ }^{13} \mathrm{C}$, respectively, using a dual $5 \mathrm{~mm}$ probe head. Deuteriochloroform and tetramethylsilane were used as a solvent and an internal standard.

Thin layer chromatographic (TLC) analysis of the monomeric dyes was followed on silica gel (Fluka $\mathrm{F}_{60} 254$ $20 \times 20 ; 0.2 \mathrm{~mm}$ ) using the solvent system $\mathrm{n}$-heptane/acetone $(1: 1)$ as an eluent.

The molecular characteristics of the poly(St-co-MD) were determined on a GPC Water 244 apparatus. The solvent was

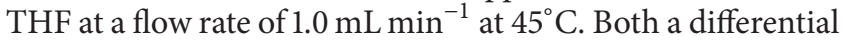
refractive index and an UV/vis absorption detector $\left(\lambda_{A}=\right.$ $375 \mathrm{~nm}$ ) were used. Polystyrene calibration was used for all molecular weight calculations.

2.2. General Procedure for Synthesis of Monomeric Dyes MD1 and MD2 (Scheme 1). 4-Amino-N-allyl-1,8-naphthalimide $(0.01 \mathrm{~mol})$ was dissolved in $50 \mathrm{~mL}$ of acetic acid and at $50^{\circ} \mathrm{C}$ $2 \mathrm{~mL}$ chloroacetyl chloride was added dropwise. The mixture was stirred at this temperature and after $2 \mathrm{~h}$ the product was isolated by pouring it into water and filtrated. After that $0.01 \mathrm{~mol}$ of this product was dissolved in dioxane and $0.05 \mathrm{~mol}$ of amines was added and stirred at $80^{\circ} \mathrm{C}$ for $4 \mathrm{~h}$. The final products have been isolated with high yields and purity.

\subsubsection{Characterization of $M D 1$}

Yield 89\%.

FTIR (KBr) cm $\mathrm{cm}^{-1}: 3248,2935,2818,1692,1651,1614$, 1538, 1380, 1235, 781.

${ }^{1} \mathrm{H}-\mathrm{NMR}\left(\mathrm{CHCl}_{3}\right) \delta(\mathrm{ppm}): 10.54(1 \mathrm{H}, \mathrm{NH}) ; 8.65-$ 8.44 (dd, 3H, Ar); 8.33-8.29 (d, 1H, Ar); 7.82-7.76 (t, $1 \mathrm{H}, \mathrm{Ar}) ; 6.08-5.92(\mathrm{~m}, 1 \mathrm{H}, \mathrm{CH}=)$; $5.36-5.17$ (dd, $1 \mathrm{H}$, $\mathrm{CH}=)$; 4.81-4.79 (d, $\left.\mathrm{CH}_{2}-\mathrm{CH}=\right)$; 3.49 (s, 2H, CO$\left.\mathrm{CH}_{2}-\right) ; 2.66$ (s, $\left.6 \mathrm{H}, \mathrm{CH}_{3}\right)$.

${ }^{13} \mathrm{C}-\mathrm{NMR}\left(\mathrm{CHCl}_{3}\right) \delta$ (ppm): 171.9, 165.1, 164.9, 140.6, 133.7, 133.0, 132.3, 129.9, 128.0, 125.2, 124, 8, 120.2, 117.6, $64.3,48.3,46.2,39.6$.

Analysis: $\mathrm{C}_{19} \mathrm{H}_{19} \mathrm{~N}_{3} \mathrm{O}_{3}\left(337.22 \mathrm{~g} \mathrm{~mol}^{-1}\right)$ : Calc. (\%): C67.67, H 5.63, N 12.46 .

Found (\%): C-67.44, H 5.69, N 12.39.

\subsubsection{Characterization of MD2}

Yield 92\%.

FTIR $(\mathrm{KBr}) \mathrm{cm}^{-1}: 3223,2946,2838,1693,1656,1620$, 1532, 1379, 1237, 777.

${ }^{1} \mathrm{H}-\mathrm{NMR}\left(\mathrm{CHCl}_{3}\right) \delta(\mathrm{ppm}): \mathrm{s} 10.44(1 \mathrm{H}, \mathrm{NH}) ; 8.66-$ 8.58 (dd, 3H, Ar); 8.29-8.20 (d, 1H, Ar); 7.85-7.79 (t, $1 \mathrm{H}, \mathrm{Ar}) ; 6.08-5.92$ (m, $1 \mathrm{H}, \mathrm{C} \underline{\mathrm{H}}-\mathrm{CH}_{2}$ ); 5.36-5.20 (dd, $2 \mathrm{H}, \mathrm{CH}_{2}=\mathrm{CH}$ ), 4.81-4.79 (d, 2H, $\left.\mathrm{CH}_{2}-\mathrm{CH}\right) ; 3.92$ (s, $\left.4 \mathrm{H}, \mathrm{CH}_{2}-\mathrm{N}-\mathrm{CH}_{2}\right) ; 3.42$ (s, $\left.2 \mathrm{H},-\mathrm{CH}_{2}-\mathrm{CO}\right) ; 3.01$ (s, $4 \mathrm{H}, \mathrm{CH}_{2}-\mathrm{O}-\mathrm{CH}_{2}$ ).

${ }^{13} \mathrm{C}-\mathrm{NMR}\left(\mathrm{CHCl}_{3}\right) \delta$ (ppm): 164.1, 163.2, 162.3, 150.3, 134.1, 130.5, 129.5, 128.3, 127.8, 124.2, 121.9, 120.0, 107.7, $103.3,55.8,45.2,44.4,39.4,30.8$.

Analysis: $\mathrm{C}_{21} \mathrm{H}_{21} \mathrm{~N}_{3} \mathrm{O}_{4}\left(379.24 \mathrm{~g} \mathrm{~mol}^{-1}\right)$ : Calc. (\%): C$66.50, \mathrm{H} 5.54, \mathrm{~N} 11.08$.

Found (\%): C-66.84, H 5.48, N 11.19.

2.3. Copolymerization. Free radical copolymerization of styrene with MDs was carried out in bulk [13]. $9.80 \mathrm{~g}$ styrene, $0.20 \mathrm{~g}$ of monomer $\mathrm{MD}$, and $0.05 \mathrm{~g} \mathrm{DBP}$ were mixed in an ampoule flushed with pure dry nitrogen. The ampoule was sealed and heated at $80^{\circ} \mathrm{C}$ in a thermostat for $8 \mathrm{~h}$. The sidechain copolymers thus obtained were several times precipitated with ethanol from the chloroform. The precipitated copolymers were repeatedly washed with ethanol, recovered by filtration, and dried in vacuum to constant weight. Transparent fluorescent copolymers of blue emission were obtained. All spectrophotometric measurements were carried out with precipitated coloured polymers. Thin polymeric film used for the fluorescent investigations was obtained from deposition of a $10 \%$ solution of the copolymer in chloroform on glass surface. The thickness of the copolymer film was $40 \mu \mathrm{m}$, determined by microscope technique. 

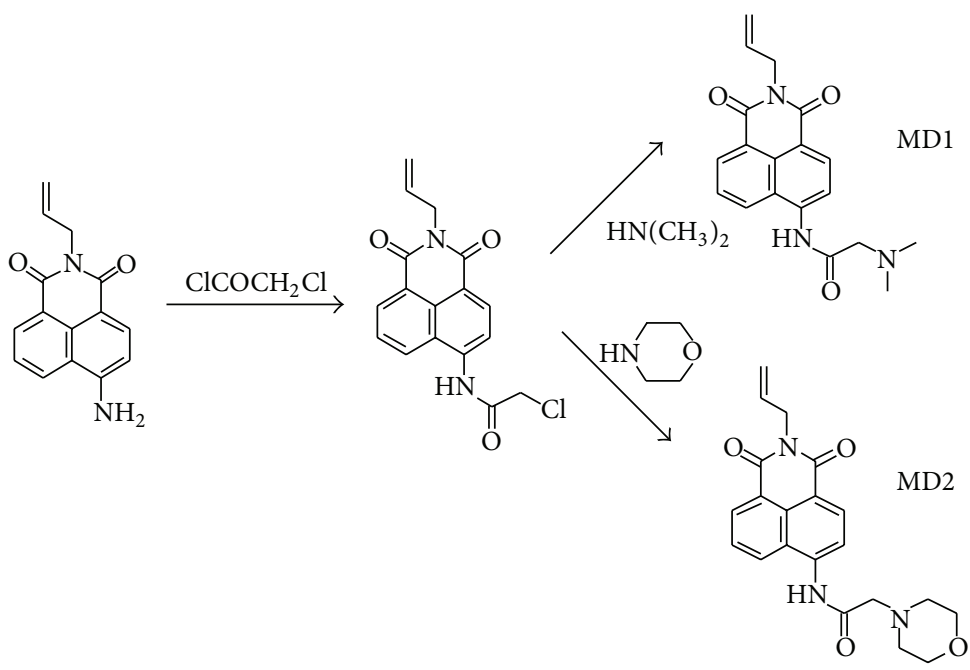

Scheme 1: Synthesis of monomeric MD1 and MD2.

\section{Results and Discussions}

3.1. Photophysical Characteristics of Monomeric and Polymeric Fluorophores. The photophysical properties of 1,8naphthalimide are known to depend mainly on the polarization of its chromophore system. In this study the functional properties of MDs were investigated in organic solvents of different polarity. Tables 1 and 2 summarize the basic photophysical characteristics of MDs-absorption $\left(\lambda_{A}\right)$ and fluorescence $\left(\lambda_{F}\right)$ maxima, Stokes shift $\left(\nu_{A}-\nu_{F}\right)$, oscillator strength $(f)$, quantum yield of fluorescence $\left(\Phi_{F}\right)$, and energetic yield of fluorescence $\left(E_{F}\right)$.

In all organic solvents under study, the monomeric 1,8naphthalimides are colourless absorbing in the ultraviolet region at $366-375 \mathrm{~nm}$ and emit blue fluorescence at 434$463 \mathrm{~nm}$. The results show that the substituents in C-4 position do not affect the maxima positions significantly.

The Stokes shift is a parameter, which indicates the difference in the properties and structure of the fluorophore between the ground state $S_{0}$ and the first excited state $S_{1}(1)$. Consider the following:

$$
\left(\nu_{A}-v_{F}\right)=\left(\frac{1}{\lambda_{A}}-\frac{1}{\lambda_{F}}\right) \times 10^{7}\left(\mathrm{~cm}^{-1}\right) .
$$

The Stokes shift values clearly depend strongly on the solvent polarity $d$. It is seen that the values are higher when alcohols are used as solvents and they were very similar to those of other monomeric 1,8-naphthalimide dyes [1416]. The Stokes shift of the MD1 has relatively high values when compared to MD2, which is probably due to the conformational changes or electron density redistribution upon excitation.

The ability of the MD molecules to emit absorbed light energy is characterized quantitatively by the quantum yield of fluorescence $\Phi_{F}$. The quantum fluorescence yield of MDs in all organic solvents was calculated on the basis of the absorption and fluorescence spectra using

$$
\Phi_{F}=\Phi_{\text {st }} \frac{S_{u}}{S_{\text {st }}} \frac{A_{\text {st }}}{A_{u}} \frac{n_{D u}{ }^{2}}{n_{D s t}{ }^{2}},
$$

where $\Phi_{\text {st }}$ is the quantum yield of the reference, $A_{\text {st }}$ and $A_{u}$ represent the absorbance of the reference and the sample, respectively, $S_{\text {st }}$ and $S_{u}$ are the integrals of the emission of the reference and the sample, respectively, and $n_{D s t}$ and $n_{D u}$ are the refractive index of the reference and the sample, respectively.

As seen from the data in Tables 1 and 2, the MDs quantum yield depends on the solvent polarity also. The quantum yield is considerably higher in nonpolar media. In polar organic solvents, the MDs exhibit much weaker emission. In all cases their fluorescence is not strong which can be explained by the conformation change.

An important characteristic of MDs is the oscillator strength $(f)$; it reveals the effective number of electrons whose transition from the ground state $S_{0}$ to the excited $S_{1}$ state gives the absorption area in the spectrum. Values of the oscillator strength can be calculated using

$$
f=4.32 \times 10^{-9} \Delta \nu_{1 / 2} \varepsilon_{\max }
$$

where the $\Delta \nu_{1 / 2}$ is the width of the absorption band (in $\mathrm{cm}^{-1}$ ) at $1 / 2 \varepsilon_{\max }$.

The values obtained for $f$ for MD1 are 0.10 (tetrahydrofuran) and 0.14 (acetonitrile). The higher values in acetonitrile correlate well with the hypsochromic effect of the MD1 in this solvent. The similar behavior has been observed also in the case of MD2.

The spectral characteristics of poly(St-co-MD) in the solid state are of interest in order to evaluate this copolymer as a heterogeneous fluorescent sensor. The copolymer was transparent and colourless, emitting blue fluorescence. The absorption and fluorescence spectra of poly(St-co-MD) in the solid state as a thin polymer film $(d=40 \mu \mathrm{m})$ are presented 
TABLE 1: Photophysical characteristics of the MD1 in organic solvents of different polarities (see text).

\begin{tabular}{|c|c|c|c|c|c|c|c|}
\hline Solvent & $\lambda_{\mathrm{abs}}(\mathrm{nm})$ & $\lambda_{\text {flu }}(\mathrm{nm})$ & $\varepsilon\left(\mathrm{L} \mathrm{mol}^{-1} \mathrm{~cm}^{-1}\right)$ & $v_{A}-v_{F}\left(\mathrm{~cm}^{-1}\right)$ & $\Phi_{F}$ & $E_{F}$ & $f$ \\
\hline Dimethyl sulfoxide & 375 & 458 & 11100 & 4833 & 0.03 & 0.03 & 0.12 \\
\hline Dimethylformamide & 374 & 452 & 11900 & 4614 & 0.03 & 0.05 & 0.12 \\
\hline Acetonitrile & 371 & 452 & 13000 & 4830 & 0.07 & 0.09 & 0.14 \\
\hline Methanol & 366 & 463 & 11900 & 5724 & 0.03 & 0.03 & 0.15 \\
\hline Ethanol & 370 & 458 & 12000 & 5193 & 0.04 & 0.04 & 0.14 \\
\hline Acetone & 372 & 450 & 12700 & 4660 & 0.01 & 0.02 & 0.13 \\
\hline Dichloromethane & 374 & 445 & 13100 & 4266 & 0.05 & 0.09 & 0.12 \\
\hline Tetrahydrofuran & 373 & 442 & 11500 & 4185 & 0.10 & 0.18 & 0.10 \\
\hline Chloroform & 374 & 440 & 11700 & 4215 & 0.08 & 0.16 & 0.11 \\
\hline
\end{tabular}

TABLE 2: Photophysical characteristics of the MD2 in organic solvents of different polarities (see text).

\begin{tabular}{|c|c|c|c|c|c|c|c|}
\hline Solvent & $\lambda_{\mathrm{abs}}(\mathrm{nm})$ & $\lambda_{\text {flu }}(\mathrm{nm})$ & $\varepsilon\left(\mathrm{L} \mathrm{mol}^{-1} \mathrm{~cm}^{-1}\right)$ & $\nu_{A}-v_{F}\left(\mathrm{~cm}^{-1}\right)$ & $\Phi_{F}$ & $E_{F}$ & $f$ \\
\hline Dimethyl sulfoxide & 375 & 451 & 11400 & 4494 & 0.04 & 0.02 & 0.11 \\
\hline Dimethylformamide & 374 & 448 & 12500 & 4417 & 0.06 & 0.03 & 0.12 \\
\hline Acetonitrile & 372 & 434 & 13200 & 3840 & 0.11 & 0.05 & 0.11 \\
\hline Methanol & 366 & 458 & 12300 & 5488 & 0.04 & 0.03 & 0.15 \\
\hline Ethanol & 370 & 450 & 11500 & 4805 & 0.05 & 0.03 & 0.12 \\
\hline Acetone & 372 & 434 & 12400 & 3840 & 0.02 & 0.01 & 0.10 \\
\hline Dichloromethane & 375 & 451 & 13400 & 4494 & 0.10 & 0.04 & 0.13 \\
\hline Tetrahydrofuran & 373 & 434 & 11500 & 3768 & 0.20 & 0.09 & 0.09 \\
\hline Chloroform & 375 & 445 & 12400 & 4195 & 0.19 & 0.06 & 0.11 \\
\hline
\end{tabular}

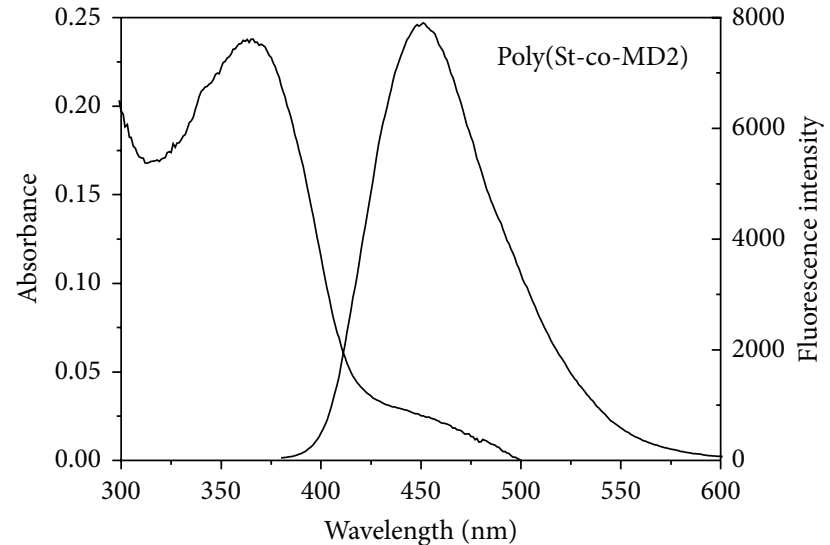

FIGURE 1: Absorption and fluorescence spectra of poly(St-co-MD2) in solid state as a thin polymer film $(d=40 \mu \mathrm{m})$.

in Figure 1, from which it is evident that the excitation and fluorescence spectra have bands with a single maximum at $365 \mathrm{~nm}$ and $450 \mathrm{~nm}$, respectively. The spectral characteristics of the former reveal that the chemical structure of the chromophoric system does not change its conformation in the solid state.

3.2. Molecular Weight and Spectral Characteristics of Poly(Stco-MD). The amount of MDs incorporated into the polymer macromolecules has been determined spectrophotometrically by using a standard curve [17]. The results show that
$1.53 \mathrm{wt} \%$ for $\mathrm{MD} 1$ and $1.45 \mathrm{wt} \%$ for MD2 have bonded to the polymer chain. Considering that the value was obtained for repeatedly precipitated copolymer where low molecular weight fractions have been removed during precipitation, the results are rather satisfactory and imply that the MDs are suitable for production of a blue fluorescent copolymer of polystyrene. This fact also demonstrated that some amount from MDs has been bonded to the low molar weight fractions of the polymer chains.

The molecular weight characteristics of the copolymers obtained are collected in Table 3. The molecular weight and molecular weight distribution confirm the formation of high molecular weight polymers. The molecular weights were found to range between $M_{w}=1.11$ and $1.34 \times 10^{-5}$ and $M_{n}=$ $0.68-0.75 \times 10^{-5}$ for copolymers with polydispersity $M_{w} / M_{n}$ 1.63 and 1.78 , respectively. The double detection shows close values for the elution time in both chromatograms indicating the presence of copolymers which absorb at about $375 \mathrm{~nm}$ in tetrahydrofuran solution.

\section{Effect of the Metal Cations on the Fluorescence Intensity of the MDs}

The photophysical properties of MDs in the presence of different metal cations $\left(\mathrm{Ag}^{+}, \mathrm{Mg}^{2+}, \mathrm{Cu}^{2+}, \mathrm{Sr}^{2+}, \mathrm{Co}^{2+}, \mathrm{Pb}^{2+}\right.$, and $\mathrm{Fe}^{3+}$ ) have been investigated in the view of their its potential sensor application. The ability of both MDs to detect metal cations has been tested in acetonitrile solution by monitoring the changes in their absorption and fluorescence spectra in the presence of various metal cations. Acetonitrile 
TABLE 3: Molecular weight and spectral characteristics in tetrahydrofuran solution of the copolymers (see text).

\begin{tabular}{lcccccc}
\hline & $M_{w} \times 10^{-5}$ & $M_{n} \times 10^{-5}$ & $M_{w} / M_{n}$ & $\lambda_{A}(\mathrm{~nm})$ & $\lambda_{F}(\mathrm{~nm})$ & $\left(\nu_{E}-\nu_{F}\right) \mathrm{cm}^{-1}$ \\
\hline Poly(St-co-MD1) & 1.11 & 0.68 & 1.63 & 375 & 421 & 2914 \\
Poly(St-co-MD2) & 1.34 & 0.75 & 1.78 & 373 & 428 & 3446 \\
\hline
\end{tabular}

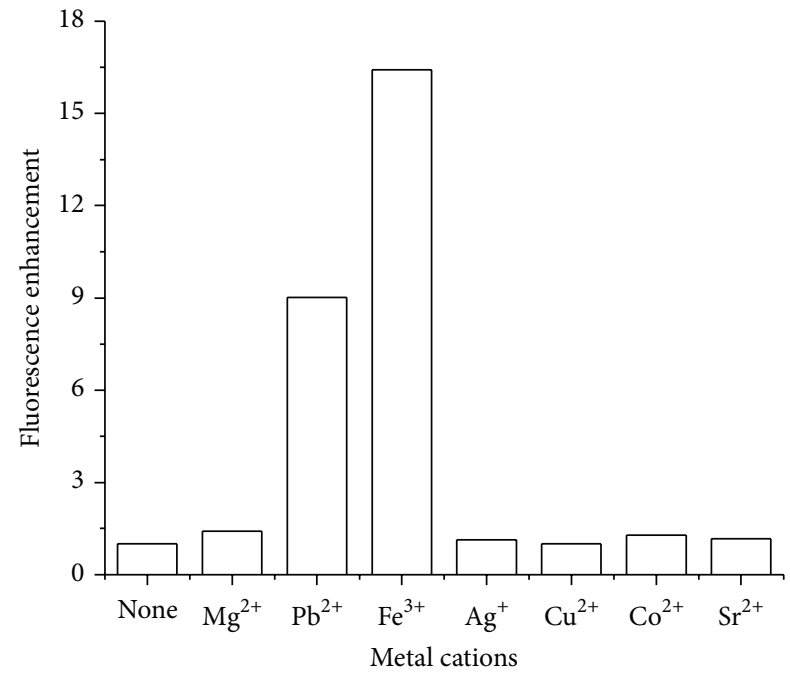

FIgURE 2: Effect of the metal cations at concentration $c=$ $10^{-5} \mathrm{~mol} \mathrm{~L}^{-1}$ on the fluorescence of MD1 in acetonitrile solution.

was chosen as solvent for all spectral measurements as it guarantee good solubility of the metal salts, ligands, and the respective complexes. Its ability to mix well with water allows direct usage of aqueous solutions of the metal salts in this study.

In the presence of the guest metal cations an enhancement or quenching of fluorescence intensity was observed. The enhancement (FE) and the quenching (FQ) of the fluorescence emission have been used as a qualitative parameter for the detection of metal cations. $\mathrm{FE}=I / I_{0}$ was determined from the ratio of maximum fluorescence intensity $I$, after the addition of metal cation, and minimum fluorescence intensity $I_{0}$, before metal cation addition. The $\mathrm{FQ}=I_{0} / I$ has been determined from the ratio between the maximum fluorescence intensity $\left(I_{0}\right.$, solution free of metal cations) and the fluorescence intensity in the presence of metal cations $(I)$.

Figures 2 and 3 present the calculated FQ and FE results for MD1 and MD2.

The highest enhancement of the monomer fluorescence intensity is observed in the presence of $\mathrm{Fe}^{3+}$ cations for compound MD1 $(\mathrm{FE}=16.42)$ as can be seen from Figure 2. In the presence of $\mathrm{Pb}^{2+}$ cations $\mathrm{MD} 1$ increases the fluorescence intensity with the respective $\mathrm{FE}=9.05$. The influence of the other cations under study $\left(\mathrm{Mg}^{2+}>\mathrm{Co}^{2+}>\mathrm{Sr}^{2+}>\mathrm{Ag}^{+}>\right.$ $\mathrm{Cu}^{2+}$ ) on the fluorescence intensity is negligible.

Figure 3 shows the fluorescence quenching of MD2 upon the addition of cations. As seen the strongest effect is again observed for $\mathrm{Fe}^{3+}$. In this case the complexation with $\mathrm{Fe}^{3+}$ cations destabilizes the planarity of the 1,8 naphthalimide molecule and as a result the fluorescence is

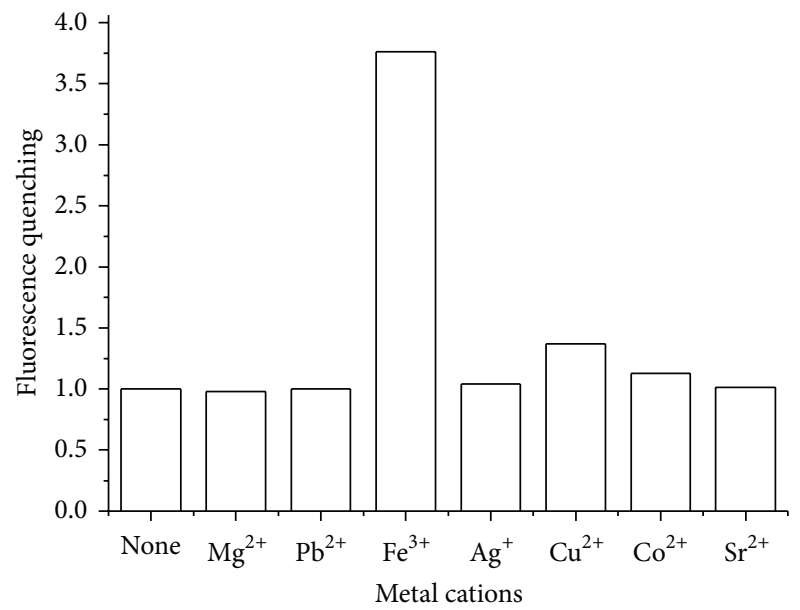

FIGURE 3: Fluorescence quenching factor of MD2 in the presence of different metal cations $\left(c=2 \times 10^{-5} \mathrm{~mol} \mathrm{~L}^{-1}\right)$ in acetonitrile solution.

quenched, while $\mathrm{Pb}^{2+}, \mathrm{Mg}^{2+}, \mathrm{Co}^{2+}, \mathrm{Sr}^{2+}, \mathrm{Cu}^{2+}$, and $\mathrm{Ag}^{+}$ cations do not affect the fluorescence intensity of the MD2. Probably MD2 does not form a stable complex with these cations.

\section{Effect of the Metal Cations on the Fluorescence of Poly(St-co-MDs)}

The presence of the guest metal cations $\left(\mathrm{Cu}^{2+}, \mathrm{Sr}^{2+}, \mathrm{Co}^{2+}\right.$, $\mathrm{Ni}^{2+}$, and $\mathrm{Fe}^{3+}$ ) in poly(St-co-MD) solution in this work is signaled by the quenching of the fluorescence intensity. The changes of the fluorescence intensity of poly(St-co-MD1) in aqueous solution, induced by the metal cations, have been investigated and the respective fluorescence responses of a polymer chromophore are presented in Figure 4. As it can be seen the addition of metal cations leads to a decrease of the polymer fluorescence intensity, different for each metal cation. In the case of $\mathrm{Cu}^{2+}, \mathrm{Sr}^{2+}, \mathrm{Co}^{2+}$, and $\mathrm{Ni}^{2+}$, the effect of metal cations on the fluorescence intensity is insignificant and the respective alteration of the fluorescent intensity is only $1-5 \%$. The highest effect was observed in the presence of $\mathrm{Fe}^{3+}$ cations. In this case the quenching of the fluorescence intensity is $96 \%$. A similar effect has been observed and in the case of poly(St-co-MD2) also. It reveals the good potential of both polymers as effective heterogeneous sensors for detection of $\mathrm{Fe}^{3+}$ ions in aqueous solutions even in the presence of other metal ions. These results were in good accordance with our other studies using polymer sensors for detecting metal ions in aqueous media [5-7]. In the form of solid polymer film these heterogeneous sensors can be 


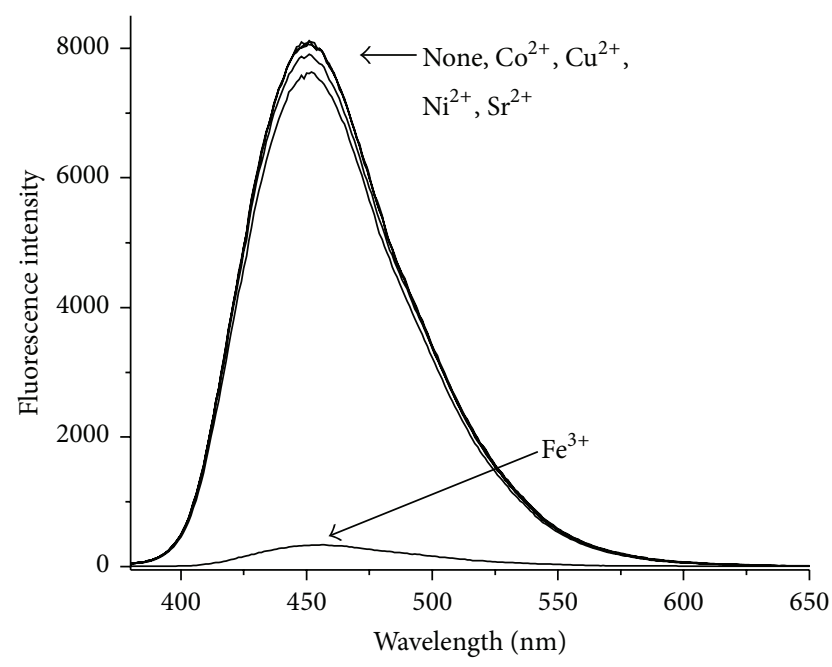

FIGURE 4: Effect of the metal cations at concentration $c=2 \times$ $10^{-4} \mathrm{~mol} \mathrm{~L}^{-1}$ on the fluorescence of poly(St-co-MD1) in aqueous solution.

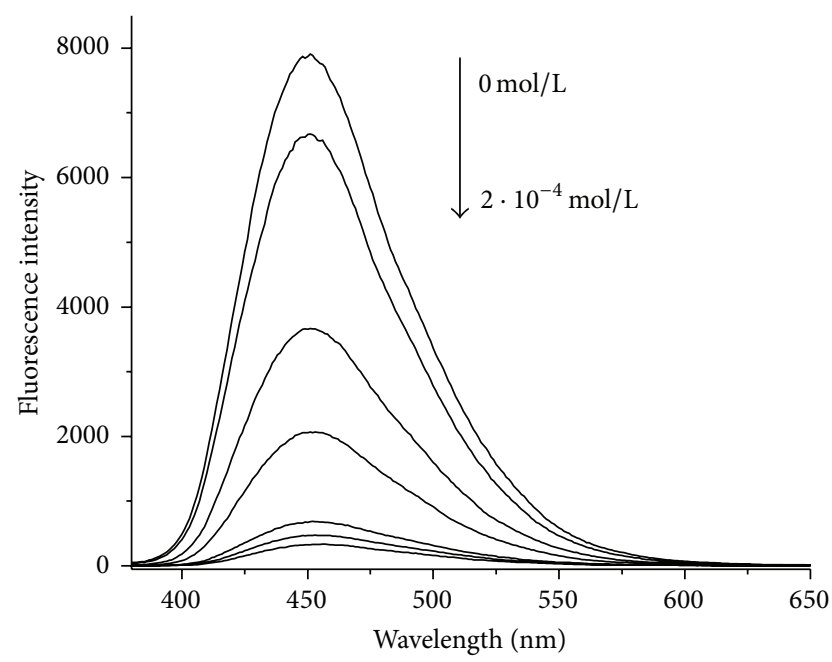

FIgURE 5: The influence of $\mathrm{Fe}^{3+}$ cations on the fluorescence intensity of the poly(St-co-MD1) at different concentrations of $\mathrm{Fe}^{3+}$ in aqueous solution.

used repeatedly for detection in aqueous solutions after prior removal of the coordinated metal ions.

The typical change in the fluorescence intensity of the copolymer induced by $\mathrm{Fe}^{3+}$ cations has been presented in Figure 5. The decrease of fluorescence intensity occurs after the addition of $\mathrm{Fe}^{3+}$ cations up to $2 \times 10^{-4} \mathrm{M}$. It is seen that the initial addition of the $\mathrm{Fe}^{3+}$ cations $\left(5 \times 10^{-5} \mathrm{M}\right)$ to the polymer leads to a decrease of the fluorescent intensity and the respective quenching effect is $31 \%$ which indicates very good sensor sensitivity. Further addition of the $\mathrm{Fe}^{3+}$ cations into the polymer solution decreases the fluorescence intensity more as can be seen in Figure 5. At high metal concentrations the fluorescence quenching is not full, which is probably due to a competition between the metal cations and the respective counterions from the solution for coordination with the chromophore site.

\section{Conclusion}

In this paper we discuss the synthesis and some functional properties of two new blue fluorescent polymerizable 1,8naphthalimides and their copolymers with styrene. The photophysical characteristics of both low and high molecular weight fluorophores have been investigated. The influence of various metal cations $\left(\mathrm{Ag}^{+}, \mathrm{Mg}^{2+}, \mathrm{Cu}^{2+}, \mathrm{Sr}^{2+}, \mathrm{Co}^{2+}\right.$, $\mathrm{Pb}^{2+}$, and $\mathrm{Fe}^{3+}$ ) on the fluorescence intensity of the new 1,8-naphthalimides has been studied with regard to their potential application as fluorescent sensors for metal ions. It has been shown that the fluorescence intensity depends strongly on the nature of metal cations. The new monomer compounds can detect $\mathrm{Pb}^{2+}$ and $\mathrm{Fe}^{3+}$. It has been shown that the blue fluorescent polymer films possess properties allowing their use as sensors for $\mathrm{Fe}^{3+}$ cations. On the basis of the present investigation it can be assumed that the new monomers and fluorescent copolymers are suitable for the selective detection of $\mathrm{Fe}^{3+}$ cations.

\section{Conflict of Interests}

The authors declare that there is no conflict of interests regarding the publication of this paper.

\section{References}

[1] M. Formica, V. Fusi, L. Giorgi, and M. Micheloni, "New fluorescent chemosensors for metal ions in solution," Coordination Chemistry Reviews, vol. 256, no. 1-2, pp. 170-192, 2012.

[2] V. Bojinov and N. Georgiev, "Molecular sensors and molecular logic gates," Journal of the University of Chemical Technology and Metallurgy, vol. 46, no. 1, pp. 3-26, 2011.

[3] B. Adhikari and S. Majumdar, "Polymers in sensor applications," Progress in Polymer Science, vol. 29, no. 7, pp. 699-766, 2004.

[4] I. Grabchev, X. Qian, Y. Xiao, and R. Zhang, "Novel heterogeneous PET fluorescent sensors selective for transition metal ions or protons: polymers regularly labelled with naphthalimide," New Journal of Chemistry, vol. 26, no. 7, pp. 920-925, 2002.

[5] I. Grabchev, J.-M. Chovelon, and V. Bojinov, "New green fluorescent polyvinylcarbazole copolymer with 1,8-naphthalimide side chains as chemosensor for iron cations," Polymers for Advanced Technologies, vol. 15, no. 7, pp. 382-386, 2004.

[6] S. Sali, S. Guittonneau, and I. Grabchev, "A novel blue fluorescent chemosensor for metal cations and protons, based on 1,8naphthalimide and its copolymer with styrene," Polymers for Advanced Technologies, vol. 17, no. 3, pp. 180-185, 2006.

[7] I. Grabchev, S. Sali, R. Betcheva, and V. Gregoriou, "New green fluorescent polymer sensors for metal cations and protons," European Polymer Journal, vol. 43, no. 10, pp. 4297-4305, 2007.

[8] P. Alaei, S. Rouhani, K. Gharanjig, and J. Ghasemi, "A new polymerizable fluorescent PET chemosensor of fluoride $\left(\mathrm{F}^{-}\right)$ based on naphthalimide-thiourea dye," Spectrochimica Acta A, vol. 90, pp. 85-92, 2012. 
[9] V. B. Bojinov, N. I. Georgiev, and N. V. Marinova, "Design and synthesis of highly photostable fluorescence sensing 1,8naphthalimide-based dyes containing s-triazine UV absorber and HALS units," Sensors and Actuators B, vol. 148, no. 1, pp. 6-16, 2010.

[10] T. N. Konstantinova, P. Meallier, and I. Grabchev, "The synthesis of some 1,8-naphthalic anhydride derivatives as dyes for polymeric materials," Dyes and Pigments, vol. 22, no. 3, pp. 191-198, 1993.

[11] D. F. Eaton, "Reference materials for fluorescence measurement," Pure and Applied Chemistry, vol. 60, no. 7, pp. 1107-1114, 1988.

[12] B. Ramachandram, G. Saroja, N. B. Sankaran, and A. Samanta, "Unusually high fluorescence enhancement of some 1,8naphthalimide derivatives induced by transition metal salts," Journal of Physical Chemistry B, vol. 104, no. 49, pp. 11824-11832, 2000.

[13] I. Grabchev, V. Bojinov, and R. Betcheva, "Spectrophotometric investigation of the copolymerization of styrene or methyl methacrylate with 1,8-naphthalimide dyes," Journal of Applied Polymer Science, vol. 81, no. 10, pp. 2463-2470, 2001.

[14] I. Grabchev, "Photophysical characteristics of polymerizable 1,8-naphthalimide dyes and their copolymers with styrene or methylmethacrylate," Dyes and Pigments, vol. 38, no. 4, pp. 219226, 1998.

[15] I. Grabchev, I. Moneva, V. Bojinov, and S. Guittonneau, "Synthesis and properties of fluorescent 1,8-naphthalimide dyes for application in liquid crystal displays," Journal of Materials Chemistry, vol. 10, no. 6, pp. 1291-1296, 2000.

[16] H. Shaki, K. Gharanjig, S. Rouhani, and A. Khosravi, "Synthesis and photophysical properties of some novel fluorescent dyes based on naphthalimide derivatives," Journal of Photochemistry and Photobiology A, vol. 216, no. 1, pp. 44-50, 2010.

[17] I. Grabchev and T. Philipova, "Fluorescent polyacrylonitrile with 1,8-naphthalimide side chains," Angewandte Makromolekulare Chemie, vol. 269, pp. 49-53, 1999. 

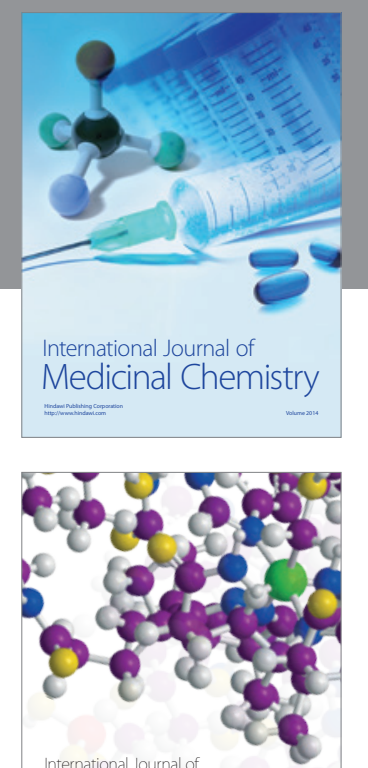

\section{Carbohydrate} Chemistry

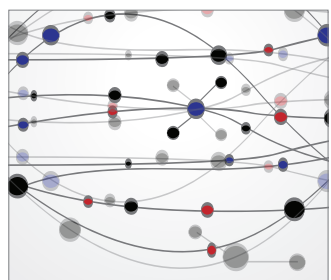

The Scientific World Journal
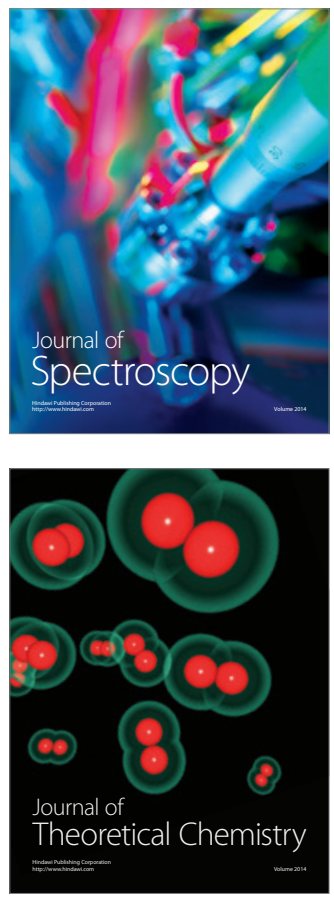
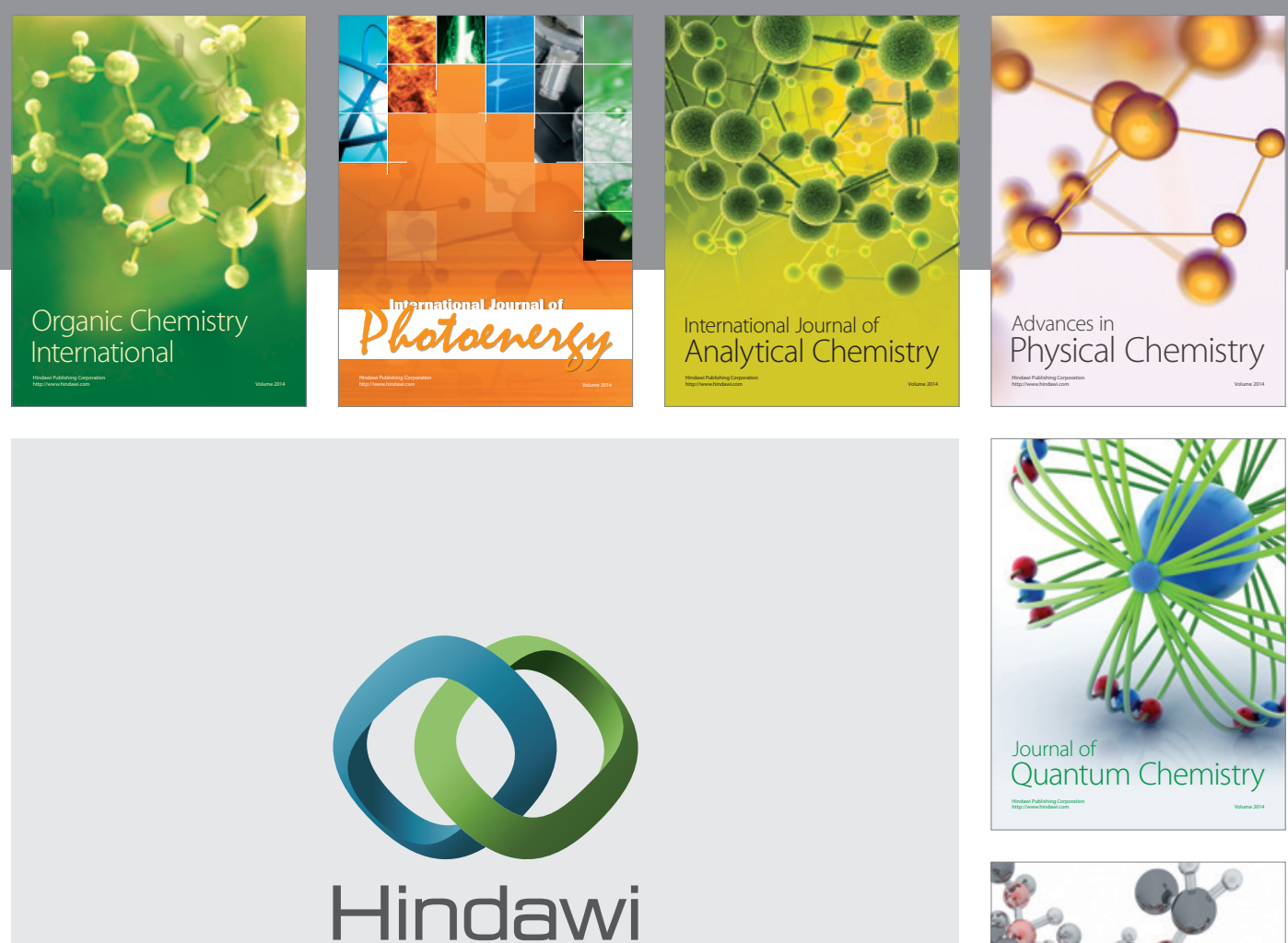

Submit your manuscripts at

http://www.hindawi.com

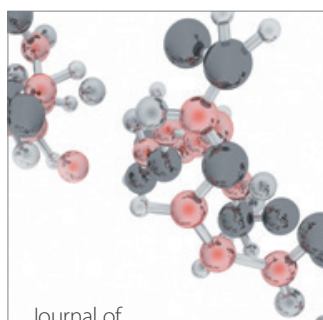

Analytical Methods

in Chemistry

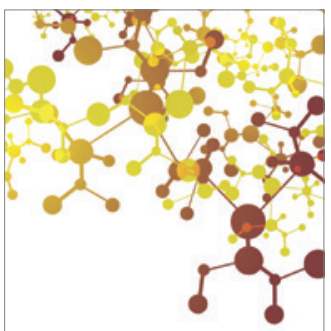

Journal of

Applied Chemistry

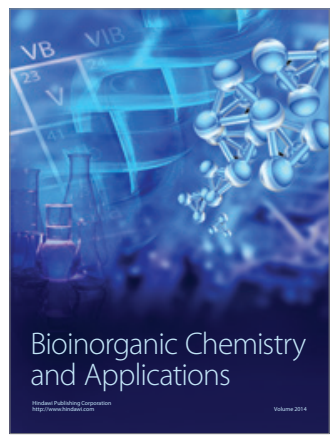

Inorganic Chemistry
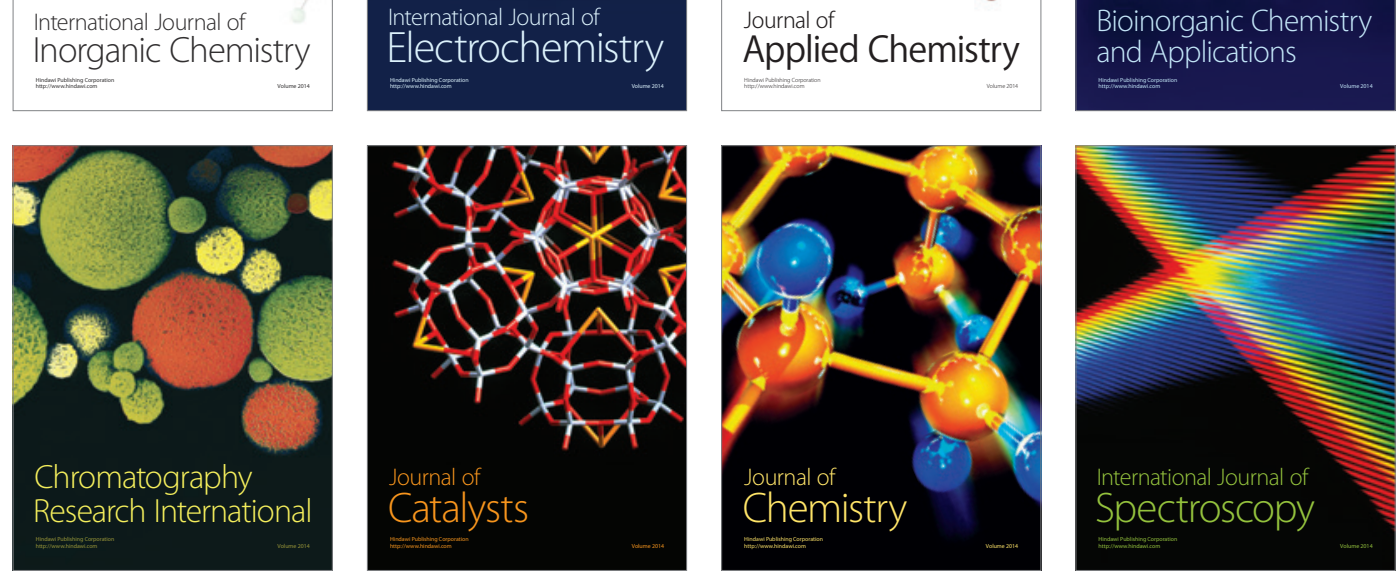